\title{
The effect of dystocia on the dry matter intake and behavior of Holstein cows
}

\author{
K. L. Proudfoot, ${ }^{*}$ J. M. Huzzey, $†$ and M. A. G. von Keyserlingk*1 \\ *Animal Welfare Program, Faculty of Land and Food Systems, University of British Columbia, Vancouver, British Columbia, V6T 1Z4, Canada \\ †Department of Animal Science, Cornell University, Ithaca, NY 14853
}

\section{ABSTRACT}

Dairy cows that have a difficult calf delivery (dystocia) are more likely to develop health complications after calving, reducing productivity and welfare. Understanding the behavioral cues of dystocia may facilitate prompt obstetric assistance and reduce the long-term effect of the challenging delivery. The aim of this study was to describe the effects of dystocia on dairy cow behavior during the period around calving and to assess the use of these behaviors as potential indicators of dystocia. Individual dry matter intake, water intake, feeding and drinking time, meal size, standing time, and number of transitions from standing to lying positions (bouts) were recorded during the 48-h period before and after the time of calf delivery for 22 Holstein cows [11 cows with dystocia and 11 cows with unassisted delivery (eutocia)]. Cows with dystocia consumed $1.9 \mathrm{~kg}$ less during the $48 \mathrm{~h}$ before calving compared with cows with eutocia ( $14.3 \pm 1.0$ vs. $16.2 \pm 1.0 \mathrm{~kg}$, respectively), and this difference increased to $2.6 \mathrm{~kg}$ in the $24 \mathrm{~h}$ before calving $(8.3 \pm 0.7$ vs. $10.9 \pm 0.7 \mathrm{~kg} / \mathrm{d})$. There were no differences in drinking time between the groups, but cows with dystocia consumed less water $24 \mathrm{~h}$ before calving $(22.4 \pm 4.4$ vs. $36.2 \pm 4.4 \mathrm{~kg} / \mathrm{d}$, respectively) and consumed more water during the 24 -h period after calving $(56.9 \pm 3.1$ vs. $48.7 \pm 3.1 \mathrm{~kg} / \mathrm{d})$ compared with cows with eutocia. Cows with dystocia transitioned from standing to lying positions more frequently than cows without dystocia beginning $24 \mathrm{~h}$ before calving $(10.9 \pm 0.7$ vs. $8.3 \pm 0.7$ bouts/d). Dry matter intake and standing bouts in the $24 \mathrm{~h}$ before calving were the most accurate variables in discriminating between cows with and without dystocia, suggesting that cows with dystocia begin to alter their behavior beginning $24 \mathrm{~h}$ before calving.

Key words: dystocia, dry matter intake, behavior, dairy cow

Received February 16, 2009.

Accepted June 5, 2009.

${ }^{1}$ Corresponding author: nina@interchange.ubc.ca

\section{INTRODUCTION}

It has been estimated that between 2 and $23 \%$ of cows in a herd experience difficult calvings that require farmer or veterinarian assistance (Mee, 2008). Calvings that are prolonged and in which the extraction of the calf is especially difficult, requiring the assistance of farm staff, are referred to as dystocia (Mee, 2004). Dystocia can result from the failure of expulsive forces during parturition, birth canal inadequacy, fetal malpositioning, and disproportionate calf size to the dam's pelvic size (Noakes et al., 2001).

Dystocia is painful (Huxley and Whay, 2006) and is associated with reduced milk yield and increased risk of health disorders and reproductive complications for the cow (Oltenacu et al., 1988) and increased risk of death for the calf (Tenhagen et al., 2007). In response to these obvious welfare and production costs, previous research on dystocia focused on identifying factors that increase the risk of dystocia. For instance, young and small cows experienced dystocia, especially when the calf was large relative to the size of the dam (Meijering, 1984; Johanson and Berger, 2003). A malpositioned calf (Meijering, 1984), abnormally short or long gestation length (Philipsson, 1976), and overfeeding and underfeeding in the last trimester (Grunert, 1979) can increase the risk of dystocia.

Some work has focused on describing behavioral changes associated with dystocia and how these changes might be applied to improve the handling of cattle experiencing a difficult delivery (Mee, 2008), but this work has largely been based on anecdotal evidence. In a study by Metz and Metz (1987), dystocia was preceded by a period of unrest characterized by frequent changes between standing and lying positions and interrupted feeding. It remains unclear how the DMI and water intake, as well as detailed feeding and standing behavior, are altered by dystocia before and after calving and if these behaviors can be used as indicators of dystocia before calving. The objective was to monitor the effect of dystocia on the behavior of cows close to the calving period and to assess these measurements as potential indicators of dystocia. We were specifically interested in behaviors that could indicate discomfort or affect the 
productivity of the cow; thus, we measured and compared DMI and water intake and feeding, drinking, and standing behavior of cows with and without dystocia from $48 \mathrm{~h}$ before to $48 \mathrm{~h}$ after calving.

\section{MATERIALS AND METHODS}

\section{Animals, Experimental Design, and Diet}

The study was conducted between August 2005 and March 2006 at the University of British Columbia's Dairy Education and Research Center (Agassiz, British Columbia, Canada). Animals were cared for according to the guidelines of the Canadian Council on Animal Care (1993). Thirty-two primiparous and 69 multiparous (parity $=3.2 \pm 1.3$, mean $\pm \mathrm{SD}$ ) Holstein cows were used. Throughout the trial, animals were housed in 3 group pens depending on stage of lactation (i.e., prepartum, maternity, and postpartum pen). Prepartum and postpartum pens contained 20 free-stalls fitted with a mattress (Pasture Mat, Promat Inc., Woodstock, Ontario, Canada) covered with $5 \mathrm{~cm}$ of sand, and stocking density was maintained at 20 animals per group. The maternity pen was the same dimensions as the pre- and postpartum pens; the free-stall hardware in this pen was removed to create a sand-bedded pack. All pens contained vulcanized rubber floors in the alleys and intersections (Red Barn Dairy Mat, North West Rubber Mats Ltd., Abbotsford, British Columbia, Canada). Each pen contained 12 Insentec electronic feed bins and 2 Insentec electronic water troughs that recorded individual intake and time spent at the feed bin per visit (Insentec, Marknesse, Holland). Chapinal et al. (2007) provided a description and validation of this feeding system.

Cows entered the prepartum pen $25 \pm 2$ d before their expected calving date and were moved to a maternity pen when they showed physical signs of imminent calving (i.e., udder enlargement, milk let-down, and relaxation of sacrosciatic ligament). Cows in the maternity pen were monitored hourly from 0500 to 2300 h. Dystocia and eutocia cows did not differ in the time spent in the maternity pen before calving (dystocia $=$ $5.8 \pm 6.0 \mathrm{~h}$, eutocia $=5.4 \pm 5.1 \mathrm{~h}$, mean $\pm \mathrm{SD}, P=$ 0.87). The maternity pen consisted of a sand-bedded pack, 6 Insentec feed bins, and 1 Insentec water trough. A maximum of 2 cows were kept in the maternity pen at any given time, and cows were moved to the postpartum pen within $16 \mathrm{~h}$ after calving. There were no differences between the time dystocia and eutocia cows were kept in the maternity pen after calving (dystocia $=8.2 \pm 6.1 \mathrm{~h}$, eutocia $=5.1 \pm 3.6 \mathrm{~h}$, mean $\pm \mathrm{SD}, P=$ $0.17)$. There were no differences in gestation length between groups; cows in both groups calved on the same day they were expected to, with a standard deviation of $4 \mathrm{~d}$. Cows in the postpartum pen were milked twice daily at approximately 0700 and $1700 \mathrm{~h}$.

Feed bins were refilled twice daily at approximately 0800 and $1600 \mathrm{~h}$. Cows in the prepartum and maternity pens were fed a TMR ad libitum consisting of $21.3 \%$ corn silage, $42.8 \%$ alfalfa hay, and $35.9 \%$ concentrate and mineral mix on a DM basis (DM: $50.8 \pm 1.2 \%$, CP: $14.4 \pm 1.0 \%$ DM, ADF: $35.0 \pm 2.7 \%$ DM, NDF: $45.6 \pm 2.6 \% \mathrm{DM}$, and $\left.\mathrm{NE}_{\mathrm{L}}: 1.4 \pm 0.1 \mathrm{Mcal} / \mathrm{kg}\right)$. Cows in the postpartum pen were fed a TMR consisting of $21.3 \%$ grass silage, $14.7 \%$ corn silage, $12.3 \%$ alfalfa hay, and $51.7 \%$ concentrate and mineral mix on a DM basis (DM: $51.1 \pm 1.8 \%, \mathrm{CP}: 17.7 \pm 1.0 \%$ DM, ADF: 23.7 $\pm 1.4 \%$ DM, NDF: $36.1 \pm 1.8 \% \mathrm{DM}$, and $\mathrm{NE}_{\mathrm{L}}: 1.66 \pm$ $0.02 \mathrm{Mcal} / \mathrm{kg})$.

\section{Dystocia Classification and Cow Participation}

Upon pelvic examination by the farm manager or 1 of 6 experienced farm staff, a cow was assisted with calving under the following criteria: 1) the calf was malpositioned, 2) the amniotic sac was ruptured and the front feet of the calf protruded for longer than $60 \mathrm{~min}$, or 3) the cervix was fully dilated but the dam was unable to deliver the calf. When assistance was considered necessary, the standard operating procedure for calving assistance was used in which the farm manager and experienced staff restrained the cow and lubricated the vaginal opening. Obstetrical (pulling) chains were then attached to the front or back feet of the calf, depending on orientation, and the feet were pulled in synchrony with the dam's contractions until the calf was fully expelled. Following calf delivery, cows were given 1 of 3 calving scores: 1 = unassisted delivery (i.e., eutocia), 2 $=$ easy assistance (i.e., one person required to pull the calf out), or 3 = difficult assistance (i.e., dystocia, 2 or more people required to pull the calf). Cows that were classified as having dystocia (calving score of 3) were compared with cows with eutocia (calving score of 1 ).

Of the 101 cows in the study, 54 cows scored 1, 23 scored 2 , and 24 scored 3 . Of the 24 cows with dystocia, 13 were removed from the final analysis because of a condition diagnosed by the herd veterinarian or hoof trimmer that might severely affect their feeding or standing time (i.e., lameness, ketosis, hypocalcemia, or retained placenta) or because they were removed to calve in another maternity pen where we were unable to monitor feed or water intake, leaving 11 cows in the final dystocia group. The behavior of these 11 cows was compared with 11 cows with eutocia; the groups were balanced for parity ( 5 primiparous and 6 multiparous cows in each group). Previous work in our laboratory showed that the occurrence of subclinical metritis post- 
calving could affect DMI during transition (see Huzzey et al., 2007); therefore, treatment groups were balanced for subclinical metritis incidence. Subclinical metritis was diagnosed using vaginal discharge scores recorded every $3 \mathrm{~d}$ postcalving until $21 \mathrm{~d}$ based on a scoring system described by Huzzey et al. (2007). Moreover, we ensured that the approximate period of calving (i.e., day or evening) and feed intake on $\mathrm{d}-4$ before calving were not statistically different between groups to reduce variation due to individual feed intake and lying behavior during the experimental period.

\section{Intake and Behavior Data Collection}

Calving time (i.e., the hour of delivery) was used as the reference point from which to analyze feed and water intake and feeding, drinking, and standing behavior preand postpartum. Calving time was determined from 2 video cameras (CCTV camera, model WV-BP330, Panasonic, Osaka, Japan) with F1.4/2.5-6 mm vari-focal lenses mounted above the feed alley and bedded pack of the maternity pen. These cameras were connected to a video multiplexer (Panasonic Video Multiplexer, WJ FS 416) and a time-lapse videocassette recorder (Panasonic Time-Lapse VCR, AG-6540), which recorded the video on VHS tapes for later use. Cows were identified on the videos by a hair-dyed alphanumeric symbol on their backs and sides. To facilitate video recording during the night hours, red lights $(100 \mathrm{~W})$ were hung adjacent to the cameras. Calving time was defined as the time at which the full calf was visibly outside of the dam. For cows that calved standing, calving time was the moment the calf hit the ground, and when cows were lying down, calving was considered the time when the back legs were completely visibly outside of the dam.

The Insentec electronic feed and water intake system was used to calculate daily feed and water intake and feeding and drinking time. Dry matter intake measures were obtained by correcting weekly as-fed intakes for the DM content of the feed. Data from the Insentec system were summarized in 24-h intervals for the period from $48 \mathrm{~h}$ before calving time to $48 \mathrm{~h}$ after the recorded time of calving. The number of meals consumed per day was computed from the Insentec data by first establishing a meal criterion. A meal criterion was the minimum time interval away from the feeder such that the next visit was considered a new meal and was identified using discontinuities in the distribution of intervals using the mixed distribution method described by Tolkamp and Kyriazakis (1999). Based on our data, a pooled meal criterion of 16.7 min was used to calculate the number of daily meals and the size and duration of each meal.
Standing behavior data were collected using modified dataloggers (Gemini Dataloggers Ltd., Chichester, UK), validated by O'Driscoll et al. (2008), which were fitted on the hind leg of each cow. These dataloggers were modified with a mercury switch that recorded leg orientation (horizontal or vertical) at 1-min intervals, and these data were used to quantify total daily standing and lying time and the number of times cows transitioned from standing to lying positions (i.e., standing bouts). Dataloggers were attached to the hind leg of cows upon entry into the prepartum pen and were removed $21 \mathrm{~d}$ postcalving; these data were offloaded weekly when cows were restrained in the milking parlor.

\section{Statistical Analysis}

Feeding and drinking variables were averaged into 24 -h periods relative to calving for analysis (i.e., $-48 \mathrm{~h}$ : 48 to $25 \mathrm{~h}$ prepartum; $-24 \mathrm{~h}: 24$ to $1 \mathrm{~h}$ prepartum; 24 h: 0 to $23 \mathrm{~h}$ postpartum; $48 \mathrm{~h}: 24$ to $47 \mathrm{~h}$ postpartum). The cow was considered the experimental unit. The PROC MIXED procedure in SAS (SAS Institute, 2003) was used to determine differences in feed and water intake and feeding and drinking behavior between cows with dystocia and eutocia. The models included the fixed effects of parity (primiparous or multiparous, df $=1), 24$-h period relative to calving $(\mathrm{df}=3)$, level of assistance (dystocia or eutocia, $\mathrm{df}=1$ ), and the period by level of assistance interaction. Cow was treated as a random effect and period as a repeated measure. When a period by level of assistance interaction $(P<0.05)$ was detected, the dependent variable was stratified by period.

The period with the most dramatic differences in feed intake occurred in the $24 \mathrm{~h}$ before calving (Figure 1). To more specifically determine the time in which cows with dystocia began to differ in DMI, we calculated the cumulative hourly intake from $24 \mathrm{~h}$ before to the hour of calving and determined the hour in which the rate of intake first differed based on the first hour in which the groups differed $(P<0.05)$ using a $t$-test in SAS.

Differences in the time between the last visit to the feeder and calving and differences in the time between calving and the first visit to the feeder were derived from the Insentec feeding system. Differences were tested using the PROC MIXED procedure in SAS (SAS Institute, 2003), and the model included parity and level of assistance as fixed effects. It was hypothesized that the time between calving and eating would affect the size of the first meal of the postpartum diet after calving; PROC REG in SAS (SAS Institute, 2003) was used to calculate an $\mathrm{R}^{2}$ value for each group to assess the relationship between these variables. Movement of cows from the maternity pen to the postpartum pen 

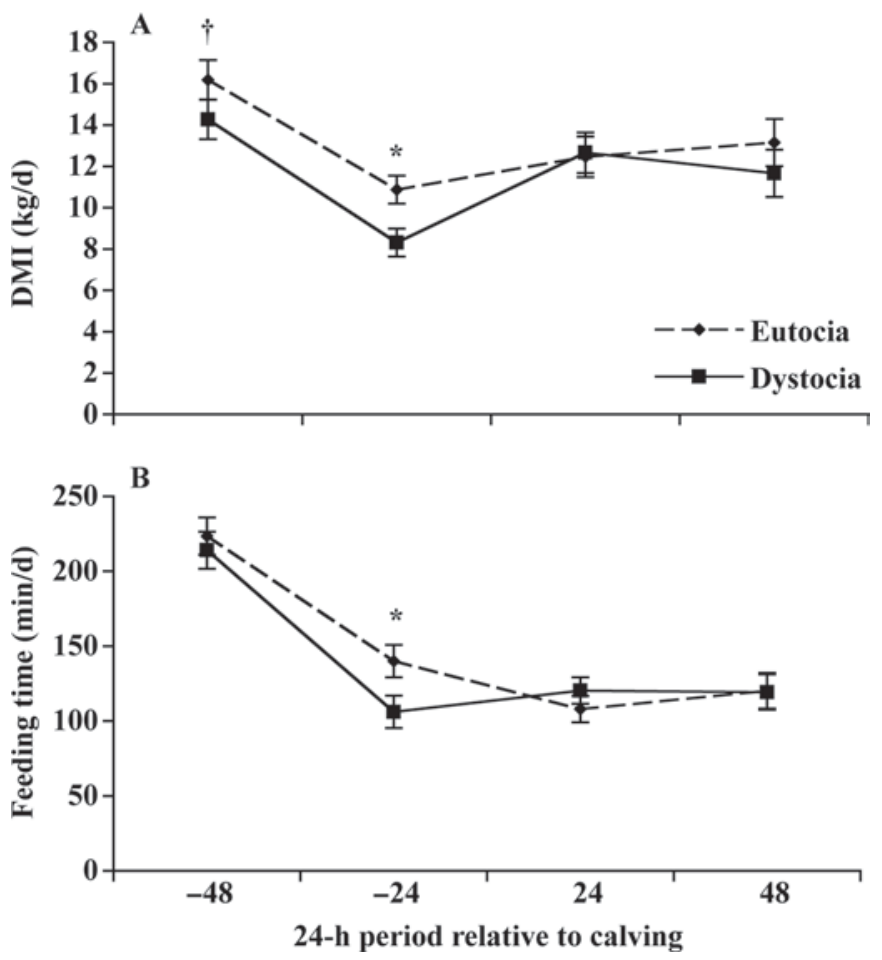

Figure 1. Daily DMI (A) and feeding time (B) during two 24-h periods before and after calving for cows with dystocia and eutocia. $\mathrm{LSM} \pm \mathrm{SE}(\mathrm{n}=11$ per treatment $) . \dagger P<0.10 ;{ }^{*} P<0.05$.

after calving was not completely controlled, resulting in cows on each treatment consuming the close-up diet after calving $($ dystocia $=2.9 \pm 2.4 \mathrm{~kg} / \mathrm{d}$, eutocia $=1.1$ $\pm 2.2 \mathrm{~kg} / \mathrm{d}$, mean $\pm \mathrm{SD})$.

The same 24-h periods were used to analyze standing behavior. Because of missing datalogger data from 1 cow in each group (1 primiparous and 1 multiparous cow), groups were rebalanced for parity, resulting in 9 animals in each group (i.e., 2 were removed from each group to maintain the same number of multiparous and primiparous cows in each group). The model used to test differences in standing variables was constructed and interpreted in the same manner as the models for the feeding and drinking variables.

To determine how well changes in behavior during the $24 \mathrm{~h}$ before calving could estimate the likelihood of dystocia, discriminant analysis using the PROC DISCRIM procedure in SAS (SAS Institute, 2003) was used. Only variables that were found to be significantly different between the 2 groups during the $24 \mathrm{~h}$ before calving $(P<0.05)$ were included in the discriminant analysis; these included DMI, feeding time, water intake, and cumulative standing bouts. Thresholds for each variable were derived using the PROC DISCRIM procedure in SAS (SAS Institute, 2003), and from these, the sensitivity (likelihood that a cow with dystocia was correctly identified as higher or lower than the threshold depending on the variable), specificity (likelihood that a cow without dystocia was correctly identified as higher or lower than the threshold depending on the variable), and accuracy (likelihood that a cow was correctly classified as having dystocia or not by the threshold) were calculated.

Milk production was automatically recorded per milking; daily milk production was calculated as a sum of the morning and afternoon milkings. To determine the effect of dystocia on milk production, the average daily milk production between wk 1 and 35 (245 DIM) postcalving was compared between the groups using a mixed model in SAS (SAS Institute, 2003). The model included the fixed effects of parity, week relative to calving, level of assistance (dystocia vs. eutocia), a week by level of assistance interaction, and a parity by level of assistance interaction, using cow as a random variable and day as a repeated measure with an autoregressive covariance structure. There was no difference in milk production $(37.5 \pm 0.65$ vs. $37.9 \pm 0.64 \mathrm{~kg} / \mathrm{d}$, dystocia vs. eutocia, $P=0.81$ ) between the 2 groups, no level of assistance by day interaction $(P=0.90)$, and no parity by level of assistance interaction $(P=0.65)$; therefore, these data will not be discussed further.

\section{RESULTS}

\section{Feed Intake and Feeding Behavior}

A period by level of assistance interaction was detected for DMI $(P=0.04)$. During the 48 -h period before calving, cows with dystocia consumed $12 \%$ less DM than cows with eutocia $(14.3 \pm 1.0$ vs. $16.2 \pm$ $1.0 \mathrm{~kg}, P=0.07$; Figure 1A) and consumed $24 \%$ less during the $24 \mathrm{~h}$ before calving $(8.3 \pm 0.7$ vs. $10.9 \pm$ $0.7 \mathrm{~kg} / \mathrm{d}, P=0.02)$. There were no differences in DMI during the 24 -h and 48 -h periods after calving between the groups.

The daily feeding time of cows with dystocia was 34 min less than that of cows without dystocia during the 24 -h period before calving $(106 \pm 11$ vs. $140 \pm 11$ $\min / \mathrm{d}, P=0.04$; Figure 1B), but this difference was not observed during any other period.

With regard to the cumulative hourly DMI during the $24 \mathrm{~h}$ before calving, cows with dystocia began to decrease their intake compared with cows with eutocia by $11 \mathrm{~h}$ before calving $(3.5 \pm 0.6$ vs. $5.3 \pm 0.6 \mathrm{~kg} / \mathrm{h}, P$ $=0.04$; Figure 2).

\section{Meals and Time to Feed After Calving}

No differences were detected in the number of meals per period between cows with dystocia and eutocia. 


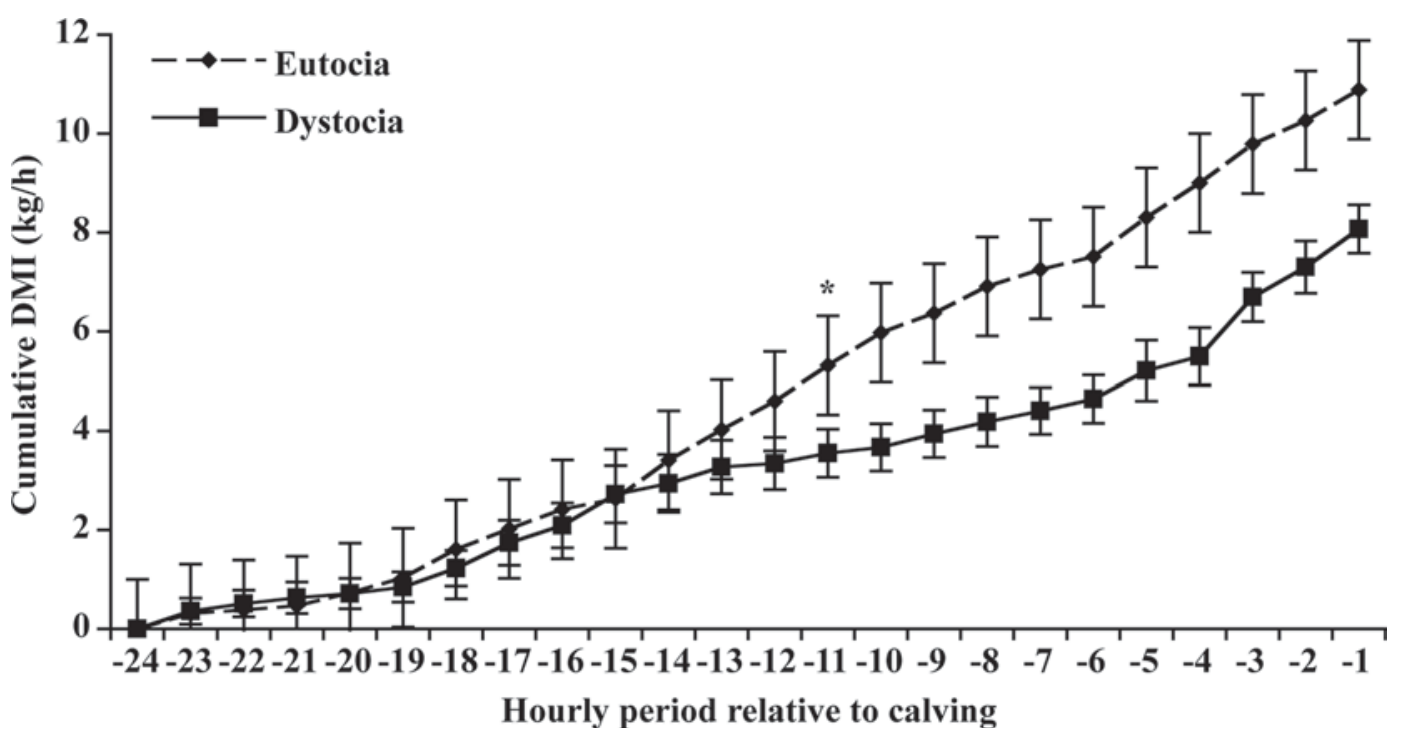

Figure 2. Hourly cumulative DMI from $-24 \mathrm{~h}$ before calving to the hour of calving for cows with dystocia and eutocia. Means $\pm \mathrm{SE}$ ( $\mathrm{n}=$ 11 per treatment). ${ }^{*} P<0.05$.

However, cows with dystocia ate smaller meals during the 48 -h period before calving $(1.4 \pm 0.1$ vs. $1.7 \pm 0.1$ $\mathrm{kg} / \mathrm{meal}, P=0.04)$ and the 24 -h period before calving $(0.8 \pm 0.1$ vs. $1.1 \pm 0.1 \mathrm{~kg} / \mathrm{meal}, P=0.01)$ compared with cows with eutocia. No differences were found in meal size after calving.

No differences were found in the time between the last visit to the feed bins and time of calving (303 \pm 71 vs. $224 \pm 71 \mathrm{~min}$, dystocia vs. eutocia, $P=0.44$ ). However, cows with dystocia had a shorter latency to visit the feed bins after calving compared with cows with eutocia ( $141 \pm 44$ vs. $326 \pm 44 \mathrm{~min}, P=0.01)$. Regression analysis revealed a positive relationship between latency to begin feeding after calving and the size of the first meal for cows with dystocia (Figure 3). The longer a cow waited to access the feeder, the larger her first meal after fresh feed delivery $\left(\mathrm{R}^{2}=0.43, P\right.$ $=0.02)$; this relationship was not found for cows with eutocia $\left(\mathrm{R}^{2}=0.01, P=0.79\right)$.

\section{Drinking Behavior and Water Intake}

During the $24 \mathrm{~h}$ before calving, cows that later had dystocia consumed less water than cows that later had eutocia $(22.4 \pm 4.4$ vs. $36.2 \pm 4.4 \mathrm{~kg} / \mathrm{d}, P=0.04$; Figure $4 \mathrm{~A}$ ). During the $24 \mathrm{~h}$ after calving, this relationship reversed; cows that had dystocia tended to consume more water $(56.9 \pm 3.1$ vs. $48.7 \pm 3.1 \mathrm{~kg} / \mathrm{d}, P=0.08)$. There were no differences in water intake between the groups during the -48 -h and +48 -h periods.

There were no differences in drinking time between cows with dystocia and cows with eutocia throughout the experimental period (Figure 4B).

\section{Standing Behavior}

No difference in standing time was found between cows with dystocia and cows with eutocia (Figure 5B). However, cows with dystocia had a higher number of cumulative standing bouts throughout the experimental period compared with cows with eutocia $(P<0.001$; Figure $5 \mathrm{~A}$ ), and this difference began during the $24 \mathrm{~h}$ before calving $(10.9 \pm 0.7$ vs. $8.3 \pm 0.7$ bouts $/ \mathrm{d})$.

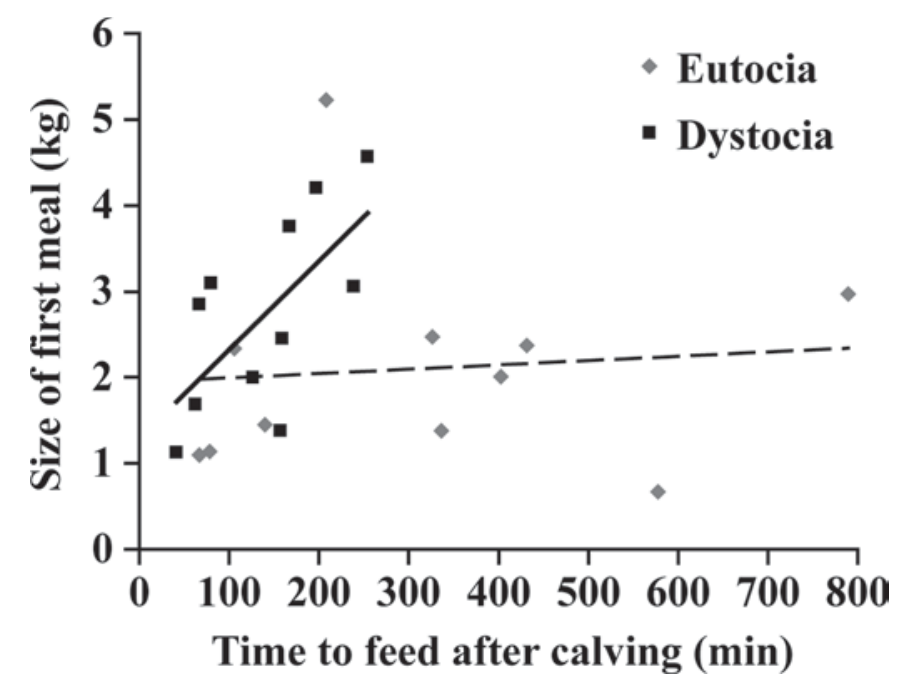

Figure 3. Relationship between the time to feed after calving and the size of the first meal after calving for cows with dystocia and eutocia $(\mathrm{n}=11$ per treatment $)$. First meal $=$ first meal after fresh feed delivery of high lactation diet. 

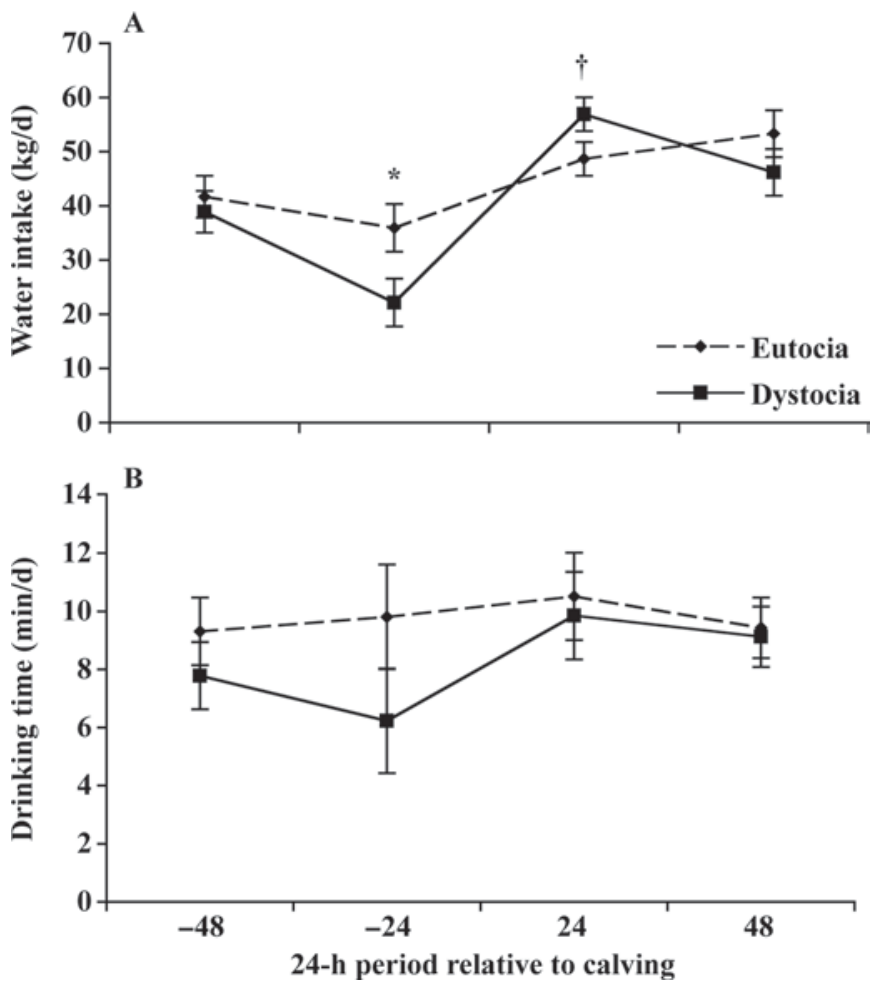

Figure 4. Average water intake (A) and drinking time (B) of cows during two 24-h periods before and after calving for cows with dystocia and eutocia. $\mathrm{LSM} \pm \mathrm{SE}(\mathrm{n}=11$ per treatment $) . \dagger P<0.10 ;{ }^{*} P$ $<0.05$.

\section{Discriminant Analysis}

Table 1 shows the thresholds, specificity, sensitivity, and accuracy of DMI, feeding time, water intake, and cumulative standing bouts during the $24 \mathrm{~h}$ before calving. Dry matter intake was accurate at detecting cows with dystocia (77.3\%); cows that ate less than $9.6 \mathrm{~kg}$ during the $24 \mathrm{~h}$ before calving were more likely to experience dystocia at calving. Cumulative standing bouts were very accurate at identifying cows with dystocia (77.8\%); cows with more than 30 bouts over the $24 \mathrm{~h}$ before calving were more likely to experience dystocia. Feeding time was moderately specific (i.e., identified cows with eutocia, $63.6 \%$ ) but did not identify cows with dystocia well.

\section{DISCUSSION}

It is clear from previous research that cows will adjust their behavior around the time of calving. For instance, Huzzey et al. (2005) showed that as calving approached, cows decreased their time spent at the feed bunk and transitioned from standing to lying positions more often. This current study is the first to show that cows with difficult calvings changed their feeding and resting behavior in a different way than did cows with unassisted calvings. To our knowledge, only 2 studies measured the effect of dystocia on cow behavior, but both monitored cows during the stages of parturition and not in the period before the onset of parturition. Wehrend et al. (2006) reported that a higher proportion of cows with dystocia rubbed against the wall, scraped the floor, and discharged urine compared with cows with eutocia, but they detected no differences in feeding or standing behavior. In contrast, Metz and Metz (1987) found that cows displayed more "unrest" behaviors in the early stages of parturition; these behaviors included frequent changes between standing and lying positions (i.e., standing bouts) and frequent, interrupted feeding. However, they were unable to measure feed intake.

A major outcome was that cows with dystocia reduced their feed and water intake, as well as feeding time, during the hours leading up to calving. These differences in behavior could be the result of several factors. For example, because dystocia is often caused by a disproportion of calf to dam size, larger calves could reduce the amount of space available in the rumen and, thus, reduce intake for cows with dystocia (Stanley et al., 1993). Alternatively, reductions in intake could be the result of pain associated with a large or malpositioned calf. According to Weary et al. (2006), one type of response to pain was a decline in the frequency or magnitude of certain behaviors that animals are highly motivated to perform, such as feeding and drinking behaviors. Although no study to date

Table 1. Specificity, sensitivity, and accuracy ${ }^{1}$ of behaviors in differentiating cows with dystocia from cows with eutocia during the $24 \mathrm{~h}$ before calving

\begin{tabular}{lcccc}
\hline Behavior & Threshold $^{2}$ & Specificity (\%) & Sensitivity (\%) & Accuracy (\%) \\
\hline DMI $(\mathrm{kg} / \mathrm{d})$ & 9.6 & 72.7 & 81.8 & 77.3 \\
Feeding time (min/d) & 103.6 & 63.6 & 54.6 & 59.1 \\
Water intake (kg/d) & 31.7 & 81.8 & 54.6 & 68.2 \\
Cumulative standing bouts (no./d) & 33.8 & 77.8 & 77.8 & 77.8 \\
\hline
\end{tabular}

${ }^{1}$ Specificity and sensitivity refer to the proportion of cows with eutocia and dystocia, respectively, that were correctly identified as higher or lower than the threshold depending on the variable. Accuracy refers to the proportion of cows that were correctly classified as having dystocia or not by the threshold of each variable.

${ }^{2}$ Thresholds for each variable were determined using discriminant analysis. 

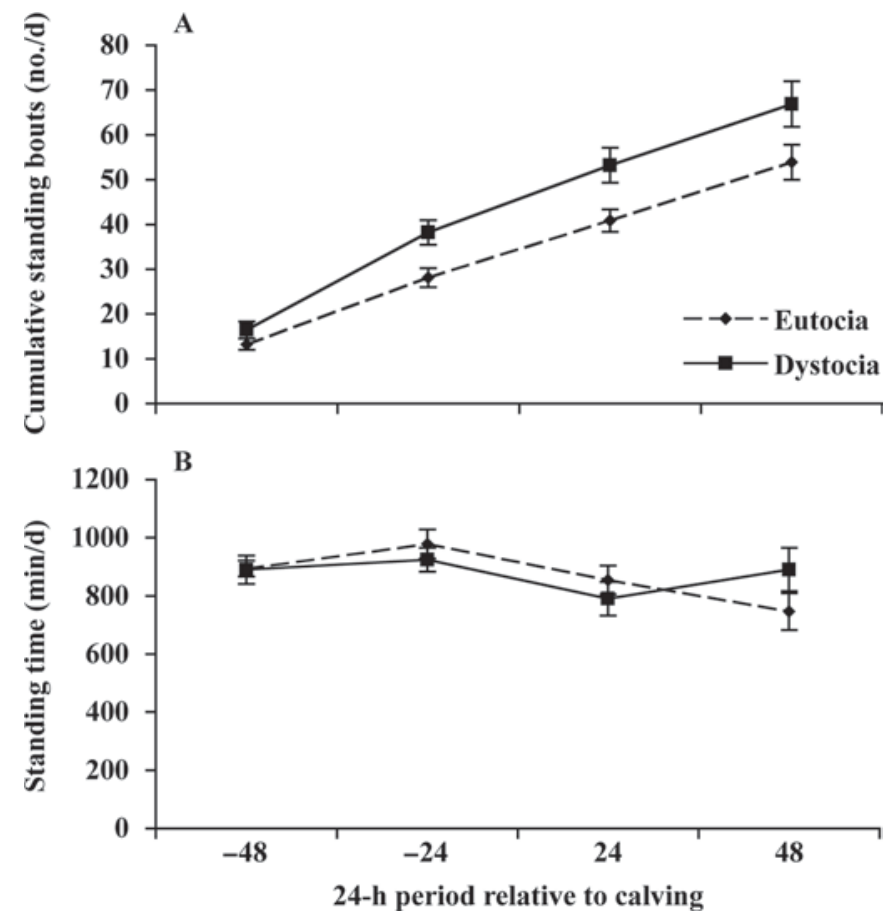

Figure 5. Number of cumulative standing bouts (A) and standing time (B) during two 24-h periods before and after calving for cows with dystocia and eutocia. $\mathrm{LSM} \pm \mathrm{SE}(\mathrm{n}=9$ per treatment).

has attempted to assess the extent of tissue damage associated with dystocia before calving, decreases in feed intake and feeding time were identified as behavioral indicators of painful lameness conditions in dairy cows (González et al., 2008). An increase in position changes before calving performed by cows with dystocia may be indicative of pain because increased general restlessness is a validated behavioral indicator of pain associated with tissue damage in other species, such as lambs following castration and tail docking (Molony and Kent, 1997). The current study was not intended to assess the level or duration of pain associated with dystocia; thus, future research should assess the physiological or psychological mechanisms before calving that drive the behavioral changes identified.

Cows with dystocia compensated for deficits in water intake before calving by tending to consume more water during the $24 \mathrm{~h}$ after calving compared with cows without dystocia. There was a greater increase in DMI for cows with dystocia between the period $24 \mathrm{~h}$ before and $24 \mathrm{~h}$ after calving compared with cows that calved without assistance and a shorter latency to eat a large meal following calving at fresh feed delivery, when cows are most motivated to access the feed bunk (DeVries et al., 2003). These results suggest that cows with difficult calvings were hungrier because of reduced intakes before calving and may be at risk for complications associated with eating a high-energy diet following a period of food deprivation. A possible outcome of feeding after a period of food deprivation is acute ruminal acidosis (Radostits et al., 1994; Garry, 2002). This study was not designed to test signs of ruminal acidosis, so more research is needed in this area.

This was the first study to show that DMI and the number of standing bouts during the $24 \mathrm{~h}$ before calving may help correctly identify cows that experience dystocia or eutocia at calving (Table 1). Although a sensitive measurement tool such as the Insentec system used in this study may be impractical for commercial use at present, the advancement of technology may soon allow use of automatic measurements of feeding and standing behavior as predictors of dystocia in the 24-h period before calving. Special attention should be given to monitoring feed intake during the brief period before calving (i.e., $11 \mathrm{~h}$ ), when cows may be showing other signs of calving (e.g., restlessness, milk let-down, and relaxation of the tail ligament).

Previous studies have used the finding that cows alter their behavior around calving as an indication that special attention and alternative management be given to transition cows (Cook and Nordlund, 2004; Huzzey et al., 2005). The current study found that cows with dystocia had exaggerated decreases in feed intake and increases in position changes compared with cows without dystocia in the $24 \mathrm{~h}$ before calving. Thus, if a maternity area with easy access to feed and water and comfortable lying space is limited, priority should be given to cows most at risk for dystocia.

\section{CONCLUSIONS}

Cows with dystocia display reduced DMI and water intake, and more frequent standing bouts during the hours leading up to calving compared with cows that calve without assistance. These reductions in highly motivated behaviors and increased restlessness may be indicative of some pain beginning up to $24 \mathrm{~h}$ before the dystocia event. In an attempt to compensate for these intake deficits before calving, cows with dystocia approach the feed bunk faster than cows with eutocia. Less time between calving and feeding was necessary for a larger first meal in cows with dystocia, potentially increasing their susceptibility to complications associated with feeding a high-energy diet following a period of food deprivation. Some behaviors identified may be useful tools in identifying cows at risk for dystocia and may help focus future research into the design of maternity pens and management of cows at risk for dystocia, such as offering priority to comfortable standing and lying surfaces and feeding programs that gradually introduce high-energy diets after calving. 


\section{ACKNOWLEDGMENTS}

The authors gratefully acknowledge the staff of the University of British Columbia (UBC) Dairy Education and Research Center. In particular, we thank Kiyomi Ito, Gianne Cunha, and Vivian Deval for their assistance in watching the maternity pen video recordings. We also thank Dan Weary (UBC, British Columbia, Canada) for his comments on an earlier version of the manuscript and Núria Chapinal (UBC, British Columbia, Canada) for her assistance with the discriminant analysis. The work was funded, in part, by a Natural Sciences and Engineering Research Council of Canada (NSERC, Ottawa, Ontario) Discovery grant awarded to M. A. G. von Keyserlingk and through an NSERC industry collaborative research grant with the Dairy Farmers of Canada, Ottawa, Ontario.

\section{REFERENCES}

Canadian Council on Animal Care. 1993. Guide to the Care and Use of Experimental Animals. Vol. 1. E. D. Olfert, B. M. Cross, and A. A. McWilliam, ed. CCAC, Ottawa, Ontario, Canada.

Chapinal, N., D. M. Veira, D. M. Weary, and M. A. G. von Keyserlingk. 2007. Validation of a system for monitoring individual feeding and drinking behavior and intake in group housed cattle. J. Dairy Sci. 90:5732-5736.

Cook, N., and K. Nordlund. 2004. Behavioral needs of the transition cow and considerations for special needs facility design. Vet. Clin. North Am. Food Anim. Pract. 20:495-520.

DeVries, T. J., M. A. G. von Keyserlingk, and K. A. Beauchemin. 2003. Diurnal feeding pattern of lactating dairy cows. J. Dairy Sci. 86:4079-4082.

Garry, F. B. 2002. Indigestion in ruminants. Pages $722-747$ in Large Animal Internal Medicine. B. P. Smith, ed. Mosby, St. Louis, MO.

González, L. A., B. J. Tolkamp, M. P. Coffey, A. Ferret, and I. Kyriazakis. 2008. Changes in feeding behavior as possible indicators for the automatic monitoring of health disorders in dairy cows. J. Dairy Sci. 91:1017-1028.

Grunert, E. 1979. Clinical aspects of the nutritional status of the dam and parturition. Pages 468-477 in Calving Problems and Early Viability of the Calf. Current Topics in Veterinary Medicine and Animal Science. Vol. 4. B. Hoffmann, I. L. Mason, and J. Schmidt, ed. Springer, New York, NY.

Huxley, J. N., and H. R. Whay. 2006. Current attitudes of cattle practitioners to pain and the use of analgesics in cattle. Vet. Rec. 159:662-668

Huzzey, J. M., D. M. Veira, D. M. Weary, and M. A. G. von Keyserlingk. 2007. Prepartum behavior and dry matter intake identify dairy cows at risk for metritis. J. Dairy Sci. 90:3220-3233.
Huzzey, J. M., M. A. G. von Keyserlingk, and D. M. Weary. 2005. Changes in feeding, drinking, and standing behavior of dairy cows during the transition period. J. Dairy Sci. 88:2454-2461.

Johanson, J. M., and P. J. Berger. 2003. Birthweight as a predictor of calving ease and perinatal mortality in Holstein cattle. J. Dairy Sci. 86:3745-3755.

Mee, J. F. 2004. Managing the dairy cow at calving time. Vet. Clin. North Am. Food Anim. Pract. 20:521-546.

Mee, J. F. 2008. Prevalence and risk factors for dystocia in dairy cattle: A review. Vet. J. 176:93-101.

Meijering, A. 1984. Dystocia and stillbirth in cattle-A review of causes, relations and implications. Livest. Prod. Sci. 11:143-177.

Metz, J., and J. H. M. Metz. 1987. Behavioural phenomena related to normal and difficult deliveries in dairy cows. Neth. J. Agric. Sci. 35:87-101.

Molony, V., and J. E. Kent. 1997. Assessment of acute pain in farm animals using behavioral and physiological measurements. J Anim. Sci. 75:266-272.

Noakes, D. E. 2001. Dystocia and other disorders associated with parturition. Pages 205-217 in Arthur's Veterinary Reproduction and Obstetrics. 8th ed. D. E. Noakes, T. J. Parkinson, and G. C. W. England, ed. Saunders, Philadelphia, PA.

O'Driscoll, K., L. Boyle, and A. Hanlon. 2008. A brief note on the validation of a system for recording lying behaviour in dairy cows. Appl. Anim. Behav. Sci. 111:195-200.

Oltenacu, P. A., A. Frick, and B. Lindhe. 1988. Use of statistical modeling and decision analysis to estimate financial losses due to dystocia and other disease in Swedish cattle. Pages 353-355 in Proc. 5th Int. Symp. Vet. Epidemiol. Econ., Copenhagen, Denmark.

Philipsson, J. 1976. Studies on calving difficulty, stillbirth and associated factors in Swedish cattle breeds. III. Genetic parameters. Acta Agric. Scand. 26:211-220.

Radostits, O. M., D. C. Blood, and C. C. Gay. 1994. Acute carbohydrate engorgement of ruminants (rumen overload). Pages 262-269 in Veterinary Medicine. O. W. Radostits, D. C. Blood, and C. C. Gay, ed. Saunders, Philadelphia, PA.

SAS Institute. 2003. SAS User's Guide. Version 9.1. SAS Inst. Inc., Cary, NC.

Stanley, T. A., R. C. Cochran, E. S. Vanzant, D. L. Harmon, and L. R. Corah. 1993. Periparturient changes in intake, ruminal capacity, and digestive characteristics in beef cows consuming alfalfa hay. J. Anim. Sci. 71:788-795.

Tenhagen, B. A., A. Helmbold, and W. Heuwieser. 2007. Effects of various degrees of dystocia in dairy cattle on calf viability, milk production, fertility and culling. J. Vet. Med. 54:98-102.

Tolkamp, B. J., and I. Kyriazakis. 1999. To split behavior into bouts, log-transform the intervals. Anim. Behav. 57:807-817.

Weary, D. M., L. Niel, F. C. Flower, and D. Fraser. 2006. Identifying and preventing pain in animals. Appl. Anim. Behav. Sci. 100:6476 .

Wehrend, A., E. Hofmann, K. Failing, and H. Bostedt. 2006. Behaviour during the first stage of labour in cattle: Influence of parity and dystocia. Appl. Anim. Behav. Sci. 100:164-170. 